\title{
SUSTANCIAS PARA INDUCCIÓN DE ENFERMEDADES EN RATAS: REVISIÓN DE LITERATURA
}

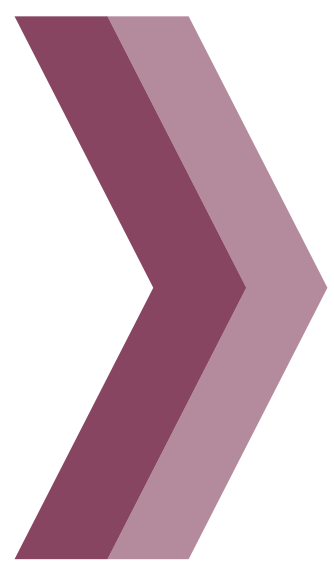

\author{
S U B S T A N C E S F R \\ DESEASE INDUCTION IN \\ RATS: LITERATURE \\ REVIEW
}

\section{Juan José Vargas Mamani ${ }^{1}$}

1. Químico Farmaceútico. Maestro en Ciencias Química de Productos Naturales. Docente de la Universidad Nacional Jorge Basadre Grohmann.

\section{RESUMEN}

Los modelos de investigación de enfermedades requiere, primero, poder reproducir enfermedades específicas en un animal como las ratas, sin llegar a ser mortal. Esto se logra con manipulación genética la cual es muy costosa debido a la adquisición de cepas endocriadas. El segundo requerimiento es inducir químicamente las patologías, lo cual requiere de sustancias específicas a dosis bien calculadas. En este artículo, recopilamos información sobre las sustancias más utilizadas y las dosis que podrían servir de referencia, así como otros datos útiles en investigación biomédica.

\section{ABSTRACT}

Disease research models require, first, to be able to reproduce specific diseases in an animal like rats, without becoming mortal. This is achieved with genetic manipulation which is very expensive due to the acquisition of inbred strains. The second requirement is to chemically induce the pathologies, which requires specific substances at well calculated doses. In this article, we collect information about the most used substances and the doses that could be used as a reference, as well as other useful data in biomedical research.

\section{INTRODUCCIÓN}

La rata de laboratorio o Rattus norvegicus fue el primer mamífero domesticado específicamente para uso científico. Es denominado también como reactivo biológico, modelo biológico, rata albina o rata de laboratorio. Es un mamífero fácil de criar, pues cuenta con una alta tasa de reproducción y requiere poco espacio. Adicionalmente, su tamaño lo hace ideal para una mejor manipulación, a diferencia de los pequeños ratones.

\section{Inducción de diabetes}

Es posible inducir la diabetes tipo II en ratas inyectando una solución de Aloxano en dosis de $40-200 \mathrm{mg} / \mathrm{kg}$ de peso o estreptozotocina en dosis de $35-65 \mathrm{mg} / \mathrm{kg}$ de peso corporal vía intravenosa o intraperitoneal. Para tanto, se deben usar ratas de 13 a 17 semanas de edad y peso mayor a $200 \mathrm{~g}$. El aloxano puede ser diluido en agua destilada al $5 \%$ o en un buffer citrato - fosfato 0.1 $\mathrm{M} \mathrm{pH} 4,5$ a una concentración de $60 \mathrm{mg} / \mathrm{ml}$ (1).

La estreptozotocina deberá ser disuelta a concentración de $0.01 \mathrm{mmol} / \mathrm{L}$ buffer citrato $\mathrm{pH} 4.5$, en ocasiones se administra en combinación con Nicotinamida a concentración de $90 \mathrm{mg} / \mathrm{Kg}$ en $\mathrm{NaCl} 0.9$ \%. En ambos casos, los efectos serán evidentes de 3 a 7 días.

\section{Inducción de úlceras gástricas}

Se reportan dos métodos: Por estrés y por indometacina. Para el primer método, las ratas deben 
ser privadas de alimento 24 horas antes de la inducción y luego deberán ponerlas en una jaula de contención flexible de malla metálica. Esta debe contener cuatro orificios localizados adecuadamente. Luego se debe asegurar el dorso del animal a fin de que las patas de la rata no toquen el suelo. Para tanto, se atan las patas para que permanezcan suspendidas horizontalmente. Las ratas se dejan en esta situación por 24 horas. La sustancia debe administrarse 24 horas antes de finalizar el experimento. Ya en el segundo método, por indometacina, las ratas deben ser privadas de alimento por 24 horas antes del experimento. La indometacina (208 mg/kg, 1,67 ml/100 g/ rata) se administrada por vía oral durante 3 días. Al cuarto día se procede al sacrificio por inhalación con éter (2).

\section{Inducción de artritis reumatoide}

Fundamentalmente, se puede inducir artritis reumatoide en ratas por dos métodos: la artritis inducida por colágeno (CIA) y artritis inducida por pristano (PIA) (3).

En el método $\mathrm{CIA}$ se usan ratas de 8 a 12 semanas de edad. El tiempo necesario para la intoxicación es de 26 días para la aguda, y 70 días para la crónica. La solución de colágeno debe ser preparada de la siguiente manera. Se usa apéndice xifoides digerida en pepsina. La digestión en pepsina debe ser extraída con solución buffer $1 \mathrm{M}$ de $\mathrm{NaCl} / 50 \mathrm{mM}$ Tris / pH 7,5, también se puede adquirir el colágeno grado reactivo. Se usa $\mathrm{NaCl}$ $0.9 \mathrm{M}$ para precipitar el colágeno. Luego, se separa el colágeno, se filtra y seca a fin de ser redisuelto posteriormente en ácido acético $0.1 \mathrm{M}$. La solución de colágeno debe ser de 150 uL de emulsión conteniendo 150 ug de colágeno disuelto en 75 uL de ácido acético $0.1 \mathrm{M} \mathrm{y}$, además, $75 \mathrm{uL}$ de coadyuvante de Freund incompleto. La inyección debe ser intradérmica cerca a las articulaciones en donde se desea producir inflamación.

En el segundo método, el método PIA, se usan ratas de 8 a 12 semanas de edad, a las cuales se inyecta $150 \mathrm{uL}$ de Pristano (2,6,10,14-Tetrametilpentadecano) de forma subcutánea en la base de la cola.

\section{Inducción de cáncer de lengua}

Es posible inducir esta patología usando oxido de 4 nitroquinolina (4NQO), el cual induce cáncer de lengua en ratas, administrando en $500 \mathrm{ml}$ de agua a una concentración de 30 ppm, 3 veces a la semana por 14 semanas aproximadamente, recordando cubrir el recipiente con cartulina negra $u$ otro material que bloquee la luz ya que este es fotosensible. El efecto debe ser confirmado con biopsia y cortes histológicos (4).

\section{Inducción de cáncer mamario}

La inducción se logra con NMU (N - nitroso - N methylurea) en una concentración de $50 \mathrm{mg} \mathrm{NMU/kg}$ de peso, disuelto en suero fisiológico, inyectado vía intraperitoneal entre los 21-50 días de edad. La solución de reactivo es estable solo por 8 horas. Los resultados serán más visibles en las 5 semanas siguientes (5).

\section{Inducción de cáncer colorectal}

Es posible inducir el cáncer colorectal en ratas wistar y spraague - dawley con DMH (dimetilhidrazina). Las concentraciones varían desde 7,4 mg/Kg hasta los 21 $\mathrm{mg} / \mathrm{Kg}$, desde una única inyección hasta 20 inyecciones, vía subcutánea, intraperitoneal o vía oral. Los efectos aparecen desde las 16 semanas hasta las 22 semanas (6).

Los autores recomiendan una administración subcutánea de $15-25 \mathrm{mg} / \mathrm{Kg}$ de peso corporal una vez a la semana por 15 - 20 semanas consecutivamente. Los efectos se comprueban por cortes histológicos, u otras pruebas que no impliquen el sacrificio de los especímenes o una biopsia que no necesite su sacrificio.

\section{Neurodegeneración inducida o simulación de parkinsonismo}

Son conocidos dos compuestos que al ser inyectados producen simular procesos neurodegenerativos como la 6 - hidroxidopamina (6-OHDA) y la 1 - metil - 4fenil - 1, 2, 3, 6 - tetrahidropiridina (MPTP). En el caso de la $6-O H D A$, se prepara en una solución salina con ácido ascórbico $(0.2 \mathrm{mg} / \mathrm{ml})$ a una concentración de 8 $\mathrm{ug} / 3 \mathrm{ul}$, a una velocidad de flujo de $1 \mathrm{ul} / \mathrm{min}$ en coordenadas establecidas según las coordenadas de la cirugía estereotáxica. La inyección es hecha en la sustancia gris directamente, $y$ debe de hacerse con un equipo de anestesia, de cirugía y una de reposo. La lesión es en la sustancia negra (7).

El efecto debe ser confirmado mediante la monitorización de los niveles de NGF (Nerve Growth Factor) o factor de crecimiento nervioso, se pueden 
hacer otras pruebas, tales como el laberinto acuático de Morris, la prueba de rotación o el test e la barra transversal, las pruebas deben ser ajustadas según lo que se desea medir a nivel de síntomas de neurodegeneración.

En cuanto a la farmacología neurodegenerativa, es posible encontrar otros modelos como lo sugieren otros autores. Es factible también la Rotenona, el paraquat (1,1-dimetil-4,4-dipiridinio), 6-OHDA (6 - hidroxidopamina) y el MPTP (1 - metil - 4 - fenil 1,2 , 3,6-tetrahidropiridinio) (8).

En cuanto a la localización de la trepanación en la rata, una localización aproximada es la incisión anteroposterior hasta exponer el cráneo, se determina el área de punción en la pars compacta derecha de la sustancia negra, según atlas de Paxinos: bregma anteroposterior $-5,0 \mathrm{~mm}$; lateral 2,1 $\mathrm{mm}$; y 7,7 mm de profundidad desde la duramadre. Se taladrara el cráneo y se inyecta con una aguja Hammilton, también se inyecta unilateralmente el 6-OHDA en una cantidad de 4 ug disuelta en 2 ul de ácido ascórbico 0,2 $\mathrm{mg} / \mathrm{ml} \mathrm{a}$ una frecuencia de $0,5 \mathrm{ul} / \mathrm{min}$. Se finaliza cubriendo con metil metacrilato la zona perforada de forma tópica, y una vez secado se sutura (9).

\section{Inducción de hiperlipemia y obesidad}

En un estudio se determinó que en ratas Spragne Dawley existe un fenotipo que puede ser inducido a obesidad manipulando su dieta, pero también existen otros fenotipos resistentes a ello, por lo que con una dieta de $21 \%$ proteínas, $31 \%$ grasa y $48 \%$ carbohidratos se puede obtener ratas obesas en el lapso de 1 mes de tratamiento. Una vez terminado el tiempo se seleccionan las ratas cuyo peso se haya incrementado en por lo menos $50 \%$ de lo que fue al inicio (10).

En otros métodos se puede administrar colesterol puro como reactivo al $97 \%$ de pureza como mínimo, administrado por vía oral en dosis de $62,5 \mathrm{mg} / \mathrm{kg}$ suspendido en goma tragacanto al $2 \%$ por un lapso de 2 meses mientras dure el experimento (11).

\section{Inducción en nefrotoxicidad}

Se logra nefrotoxicidad administrando acetato de plomo en una concentración de $30 \mathrm{mg} / \mathrm{Kg}$ de peso por vía oral una vez al día por 60 días. La toxicidad consiste en necrosis de los túbulos renales, los efectos se observan después de 60 días. La nefrotoxicidad se comprueba midiendo el clearance de creatinina, el nitrógeno ureico en sangre, el malonildialdehido, la superoxido dismutasa y el glutation peroxidasa (12).

\section{Inducción de arritmia}

Existen diversos métodos para provocar arritmias en ratas, tanto químicas como eléctricas. Entre ellos podemos mencionar a dos, los cuales son los más accesibles, teniendo presente que para poder monitorizar y probar el efecto, es necesario utilizar un kimografo o un equipo de ECG lo suficientemente sensible para detectar los latidos del espécimen. Sin embargo, la administración de glicosidos cardiacos ha demostrado eficiencia en especies más grandes como conejos, o perros, por ejemplo, la ouabaina y la aconitina. Contrariamente, la rata ha demostrado relativa resistencia a esos tratamientos por lo que se recomienda la lesión quirúrgica como alternativa o el uso de corazón aislado en vez del animal entero (13).

Se puede provocar arritmia, mediante una inyección de $\mathrm{CaCl}_{2} 2.5 \%$ en una proporción de $140 \mathrm{mg} / \mathrm{kg}$ de peso corporal de la rata al día 1 y al día 27 , es decir dos veces, además en ese lapso de tiempo se debe someter al espécimen a un protocolo para provocar estrés. El estrés se logra colocando el animal en una caja restrictiva, de tal manera que no pueda moverse en absoluto, haciendo uso de sujetadores de metal u otros instrumentos por un periodo de 21 días 6 horas al día. La inyección se hace en la vena femoral, la cual previamente debe ser expuesta por cirugía. Adicionalmente, la rata anestesiada debe ser monitorizada antes y después de la inyección. Los efectos se apreciaran mejor con un kimografo (14).

Se puede inducir la arritmia mediante una inyección en la arteria carótida de digoxina $0.5 \mathrm{mg} / 2 \mathrm{ml}$ en un rango de $5 \mathrm{ug} / \mathrm{kg} / \mathrm{min}$ por $60 \mathrm{~min}$ como mínimo y 40 $\mathrm{ug} / \mathrm{kg} / \mathrm{min}$ por 10 min como máximo; seguidamente, se obtiene una prolongación QT. Los efectos se deben observar de inmediato en el kimografo (15).

En ambos casos se debe llevar la anestesia con cuidado usando una combinación de anestésicos generales y auxiliares con el fin de reducir los efectos adversos.

\section{Inducción de inflamación en extremidades}

Es posible producir inflamación en las patas del animal, con una inyección de carragenina al $1 \%$ en suero fisiológico. Se inyecta en la pata, en la región 
metatarsiana, en la parte posterior derecha, los efectos se podrán apreciar y medir a las tres horas de la inyección. La inflamación es medida por desplazamiento de mercurio en un equipo de vidrio, similar al recipiente florentino, del tamaño justo para la introducción de la pata de la rata y una bureta lo suficientemente pequeña para medir el mercurio desplazado por el volumen. Antes de efectuar la medición, se debe marcar con una línea la zona a medir en la pata (16).

\section{Inducción de hipertensión}

Se puede producir hipertensión en ratas, mediante la administración de $\mathrm{L}$ - NAME ( $\mathrm{Ng}$ - nitro $\mathrm{L}$ - arginina) en dosis de $50 \mathrm{mg} / \mathrm{kg}$ vía oral una vez al día por dos días. La medición de la presión se efectúa del tercer al décimo día. Es necesario ajustar la dosis y medir la presión con un equipo especialmente adaptado para ese fin (17).

\section{REFERENCIAS BIBLIOGRÁFICA}

1. Aranda - Ventura José, Villacrés Jorge, Mego Rosario, Delgado Henry. Efecto de los extractos de Geranium ayavacense w. (Pasuchaca) sobre la glicemia en ratas con diabetes mellitus experimental. Rev Perú Med Exp Salud Pública. Perú; 2014; 31(2): 261-266.

2. Ccoa Norma. Efecto citoprotectivo del "chaco" en lesiones gástricas inducidas por estrés e indometacina. Acta Médica Agustina. Perú. 1997; vol VII-VIII; 44-48.

3. Weikun Hou, Liesu Meng, Conghsan Jiang, Shemin Lu. A systematic comparison between collagen - induced arthritis and pristane - induced arthritis in Dark Agouti rats. clinical and experimental rheumatology. China. 2010; 28: 532-538.

4. Monir Moradzadeh Khiavi, Ahamd Rostami, Hamed Hamishekar, Mehran Mesgari Abassi. Therapeutic efficacy of orally delivered doxorubicin nanoparticles in rat tongue cancer induced by 4 - nitroquinoline 1 - oxide. advanced pharmaceutical bulletin. Iran. 2015, 5(2), 209-216.

5. Teicher Beverly. Tumor Models in Cancer Research. USA: Humana Press; 2002.

6. Perse Martina, Cerar Anton. The dimethylhydrazine induced colorectal tumours in rat experimental colorectal carcinogénesis. Radiol Oncol. Eslovenia. 2005; 39(1): 61-70.

7. Lorigados Pedre Lourdes, Pavón Fuentes Nancy, Serrano Sánchez Teresa, Blanco Lescano lisette. Modelos experimentales de neurodegeneración: tratamiento restaurativo y factor de crecimiento nervioso. Revista mexicana de neurociencia. México. 2009; 10(4): 264-273.

8. Alarcón Adriana, Abel Santamaría del Angel, Mina Königsberg. Modelos neurotóxicos e la enfermedad de parkinson y disfunción mitocondrial. México. 2010. 29(3): 92100.

9. Mejia Dolores Jhon, Mendoza Quispe Daniel, Moreno Rumay Edwin, Gonzales Carlos, Remuzgo Fany. Efecto neurotóxico del extracto acuoso de boldo (Peumus boldus) en un modelo animal. Rev Perú Med Exp Salud Pública. 2014; 31(1): 62-68.

10. Barry Levin, Ambrose Dunn - Meynell, Bork Balkan, Richard E. Keesey. Selective breeeding for diet - induced obesity and resistance in Sprague - Dawley rats. American J. Physiological Society. Usa. 1997. 42; R725-R70.

11. Arroyo Jorge, Raez Ernesto, Rodriguez Miguel, Chumpitaz Victor. Reducción del colesterol y aumento de la capacidad antioxidante por el consumo crónico de maíz morado (Zea maíz L) en ratas hipercolesterolémicas. Rev Perú Med Exp Salud Pública. Perú. 2007; 24(2): 157-162.

12. Sri Agus Sudjarwo, Koeniasari Eraiko, Giftania Wardani, Koerniasari. Protective effects of piperine on lead acetate induced nefrotoxicity in rats. Iranian Journal of basic medical sciences. Indonesia. 2017; Vol. 20, № 11, 1227-1232.

13. Cheung P.H, Pugsley M.K, Walker M.A. Arrhythmia models in the Rat. Journal of Pharmacological and Toxicological methods. Canada. 1993; 29(4): 179-184.

14. Mahin Dianat, Negin Amíni, Mohammad Badavi, Yaghoub Farbood. Ellagic acid improved arrhythmias induced by $\mathrm{CaCl} 2$ in the rat stress model. Avicena Journal of Phytomedicine,. Iran. 2015; vol 5, no 2; 120-127.

15. Hayrullah Alp, Burak Cem Soner, Tainer Baysal, Ayse Saide Sahin. Protective effects of hawthorn (Crataegus oxyacantha) extract against digoxin - induced arrythmias in rats. Anatol J. Cardiology. Turquía. 2015; 15: 970-975.

16. Ahmed Salama, Lya Duque, Francy Díaz. Actividad antiinflamatoria, dosis letal 50 y estudio fitoquímico preliminar de Cucumis anguria. Revista colombiana de ciencias químico farmacéuticas. Colombia. 1994, no 22; 42-46.

17. Rojas juan, Ronceros Sergio, Palomino Robert, Gloria Tomas. Efecto antihipertensivo y dosis letal 50 del jugo del fruto y del extracto etanólico de las hojas de Pasiflora edulis (maracuya), en ratas. Anales de la facultad de medicina de la UNMSM. Perú. 2006; 67(3): 206-213.

\section{Correspondencia}

Juan José Vargas Mamani

Ogiva64@gmail.com
Fecha de recepción: 12 de julio de 2018

Fecha de aceptación: 10 de diciembre de 2018 